
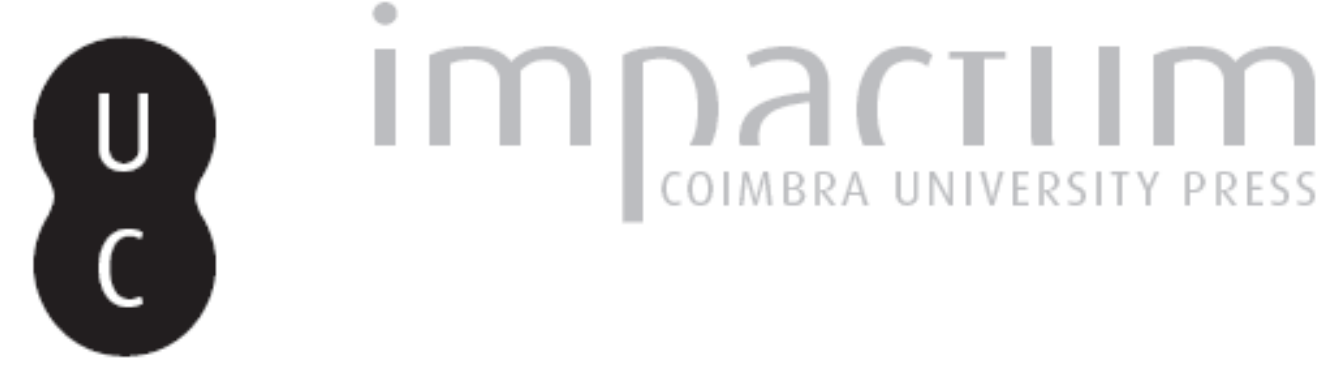

\title{
Cultura material e diplomacia eclesiástica: as relações e a troca de presentes entre o bispo-conde de Coimbra D. Afonso de Castelo Branco e a corte papal (1590-1615)
}

Autor(es): $\quad$ Marques, Cátia Teles e

Publicado por: Centro de História da Sociedade e da Cultura

URL

persistente:

URI:http://hdl.handle.net/10316.2/39365

DOI:

DOI:http://dx.doi.org/10.14195/1645-2259_14_7

Accessed : $\quad$ 26-Apr-2023 09:54:54

A navegação consulta e descarregamento dos títulos inseridos nas Bibliotecas Digitais UC Digitalis, UC Pombalina e UC Impactum, pressupõem a aceitação plena e sem reservas dos Termos e Condições de Uso destas Bibliotecas Digitais, disponíveis em https://digitalis.uc.pt/pt-pt/termos.

Conforme exposto nos referidos Termos e Condições de Uso, o descarregamento de títulos de acesso restrito requer uma licença válida de autorização devendo o utilizador aceder ao(s) documento(s) a partir de um endereço de IP da instituição detentora da supramencionada licença.

Ao utilizador é apenas permitido o descarregamento para uso pessoal, pelo que o emprego do(s) título(s) descarregado(s) para outro fim, designadamente comercial, carece de autorização do respetivo autor ou editor da obra.

Na medida em que todas as obras da UC Digitalis se encontram protegidas pelo Código do Direito de Autor e Direitos Conexos e demais legislação aplicável, toda a cópia, parcial ou total, deste documento, nos casos em que é legalmente admitida, deverá conter ou fazer-se acompanhar por este aviso.

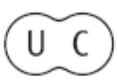




\section{4 \\ 2014}

\section{evista de História da Sociedade e da Cultura}

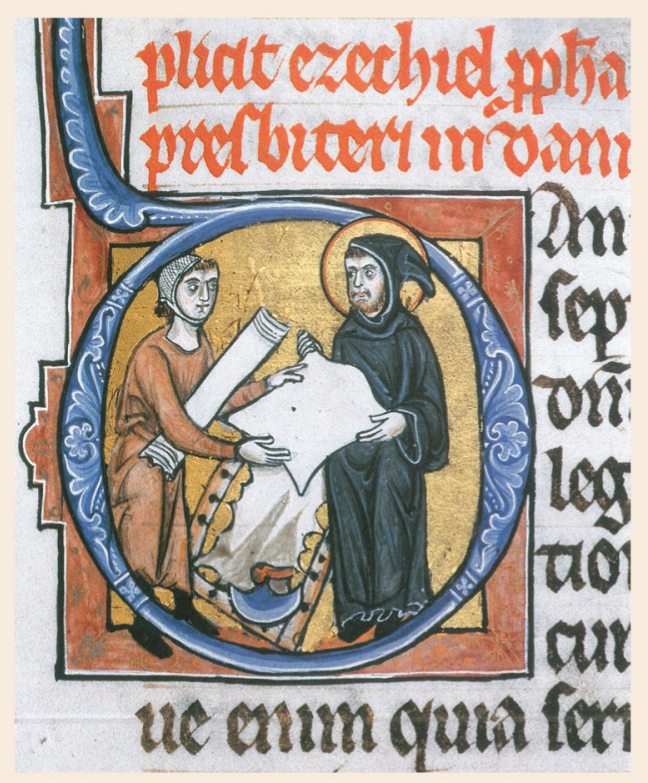

Centro de História da Sociedade e da Cultura Universidade de Coimbra 


\title{
Cultura material e diplomacia eclesiástica. As relações e a troca de presentes entre o bispo-conde de Coimbra D. Afonso de Castelo Branco e a corte papal (1590-1615)*
}

\author{
Cátia Teles e Marques \\ Centro de História d'Aquém e d'Além Mar \\ Faculdade de Ciências Sociais e Humanas, Universidade Nova de Lisboa, \\ Universidade dos Açores \\ catiatelesemarques@gmail.com \\ Texto recebido em/Text submitted on: 20.05.2014 \\ Texto aprovado em/Text approved on: 05.10.2014
}

Resumo/Abstract:

O presente artigo constitui uma aproximação ao tema da cultura material associado à diplomacia praticada pelo clero português, partindo do estudo de caso de $\mathrm{D}$. Afonso de Castelo Branco, bispo-conde de Coimbra. Tomando por fonte principal a correspondência conservada no Archivio Segreto Vaticano, estudam-se as redes clientelares de D. Afonso em Roma, esclarecendo quem eram os seus agentes e contactos e os destinatários das suas ofertas. Seguidamente, identificam-se e caracterizam-se os artigos seleccionados por D. Afonso de Castelo Branco para oferecer aos papas e cardeais - pedras bezoar, contas de calambuco, porcelanas e luvas de âmbar. Por último, é dada atenção aos mecanismos de consumo e estratégias diplomáticas de D. Afonso de Castelo Branco, reflectindo sobre a finalidade do seu investimento.

In this article I address the topics of material culture and Portuguese ecclesiastical diplomacy by analysing the case study of Afonso de Castelo Branco, bishop-count of Coimbra. The bishop's correspondence kept in Archivio Segreto Vaticano made possible not only to ascertain who were his agents and contacts in Rome and the recipients of his diplomatic gifts, but also to identify the goods he selected for popes and cardinals - bezoar stones, beads of calambuco, porcelains and amber gloves. Finally, I take into consideration Afonso Castelo Branco's means of consumption and diplomatic strategies assessing the purpose of his investment.

Palavras chave/Keywords:

Presentes diplomáticos; Consumo; Mercadorias da carreira da Índia; Luvas de âmbar; Portugal dos Filipes.

Diplomatic gifts; Consumption; Goods from Portuguese India trade route; Amber gloves, Habsburg Portugal.

* Este estudo decorre da investigação realizada na minha Tese de Doutoramento, que decorreu com o apoio de uma Bolsa de Doutoramento da Fundação para a Ciência e Tecnologia (SFRH / BD / 45995 / 2008). O desenvolvimento de alguns dos tópicos analisados neste artigo beneficiou da participação no grupo de trabalho "Consumo artístico em Portugal na Idade Moderna", sedeado no CHAM - FCSH/NOVA-UAc e coordenado por Nuno Senos (2014). Foram também importantes as sugestões críticas de Carla Alferes Pinto e dos referees anónimos. Registo aqui o meu agradecimento a todos os referidos. 
Também se toma a palavra Luvas, mais geralmente por qualquer cousa que se dá à pessoa, da qual temos recebido algum beneficio.

Padre Rafael Bluteau, Vocabulario Portuguez \& Latino,

1728, vol. V, p. 213.

O tema da cultura material associado à diplomacia levanta questões muito particulares acerca do consumo na Época Moderna que têm andado arredadas do interesse da historiografia portuguesa, muito em particular tratando-se da esfera do clero. Que objectos eram oferecidos e quais os critérios da selecção? De que forma se agenciava a aquisição, o envio e a entrega? E qual a finalidade das ofertas entre representantes da Igreja?

O presente artigo procura problematizar estas questões à luz do estudo de caso do bispo-conde de Coimbra D. Afonso de Castelo Branco. A partir da correspondência conservada no Archivio Segreto Vaticano, revela-se a teia das relações diplomáticas do bispo-conde com a corte papal entre as décadas de 1590 e 1610, esclarecendo quem eram os seus agentes e contactos em Roma e os destinatários das suas ofertas. Seguidamente, identifica-se e caracteriza-se o universo dos artigos seleccionados por D. Afonso de Castelo Branco para agraciar papas e cardeais, analisando as suas escolhas no quadro da cultura material das elites portuguesas e da divulgação das mercadorias trazidas pelas naus das Índias. Finalmente, é dada atenção aos mecanismos de consumo e estratégias diplomáticas de D. Afonso de Castelo Branco, reflectindo sobre o propósito do investimento em ofertas sofisticadas.

Importa começar por apresentar D. Afonso de Castelo Branco (c. 1522-1615). D. Afonso distinguiu-se pela carreira notável que prosseguiu com o favor régio, tendo-lhe sido confiados importantes cargos eclesiásticos e oficiais do Reino. O seu reconhecimento ocorreu nos reinados de D. Sebastião e do cardeal D. Henrique ${ }^{1}$, mas foi com Filipe II e Filipe III que o seu estatuto e poder se consolidou com as nomeações para bispo do Algarve

1 Entre os cargos desempenhados ao serviço dos reis da dinastia de Avis-Beja, destacam-se os de deputado da Mesa da Consciência e Ordens (1572); comissário-geral da Bula da Cruzada; esmoler e capelão de D. Sebastião (1577); esmoler-mor, conselheiro e deão da capela de D. Henrique. 
(1581-1585), bispo-conde de Coimbra (1585-1615); e vice-rei de Portugal (1603-1604). De todos os cargos, aquele que conferiu maior notoriedade a D. Afonso foi a prelazia de Coimbra, não só pela longa duração da mesma, como pela relevância da diocese no mapa episcopal português.

Coimbra era bispado principal de Portugal, situando-se, em importância, logo a seguir aos arcebispados de Braga, Lisboa e Évora, com rendas consideradas «muito pingues e opulentas», rondando os 40 ou $50 \mathrm{mil}$ cruzados $^{2}$. D. Afonso pôde, assim, investir na aquisição dos artigos dispendiosos para presentear a corte papal que se tratam neste estudo, como também no patrocínio de um importante programa de obras de arquitectura em Coimbra e na encomenda de obras de arte que o distinguiram, à época, como prelado liberal e magnificente ${ }^{3}$. A sua memória foi aclamada e enaltecida em variadas publicações e crónicas da época, nomeadamente na biografia redigida por João de Almeida Soares e intitulada Vida, e morte, de Dom Afonso Castelbranco Bispo de Coimbra Conde de Arganil, Senhor de Coja, e Alcaide mor de Arouca, Vizo Rei deste Reino dito Portugal ${ }^{4}$.

\section{Relações diplomáticas e contactos com a cúria romana}

Na corte papal eram, igualmente, recebidas notícias de Lisboa a respeito de D. Afonso de Castelo Branco que faziam constar a opinião de ser um prelado devoto da Sede Apostólica e muito liberal nas «obras pias e cristãs», dando bom uso aos avultados réditos de que dispunha:

Degli altri Prelati del Regno, che potriano aiutar, c'è Coimbra, che hà buone entrate, et si mostra devotissimo della Sede Apostolica,

2 ALMEIDA, Fortunato - História da Igreja em Portugal. Lisboa: Livraria Civilização Editora, 1968, vol. II, p 96-99. MARQUES, Cátia Teles e - A sacristia e a encomenda episcopal em Portugal no período da Reforma Católica. O caso da Sé de Coimbra e o patrocínio do bispo D. Afonso de Castelo Branco. Lisboa: [s.n.], 2013. Tese de Doutoramento em História da Arte Moderna apresentada à Faculdade de Ciências Sociais e Humanas da Universidade Nova de Lisboa. p. 201-202.

3 MARQUES, Cátia Teles e - A sacristia e a encomenda ..., cit., p. 229-257.

4 Embora a biografia não tenha chegado a ser dada à estampa, é admissível que tenha circulado em manuscrito, conhecendo-se três cópias: Biblioteca da Academia das Ciências de Lisboa, Ms. 194 Vermelho; Biblioteca Pública de Évora, Cod. CIV e CV. 
et è molto liberali in opere pie, et sempre, che S. S. ${ }^{\text {tà }}$ gli mandi un breve amorevole conforme a gli altri, mi persuado, che farà buono effetto ${ }^{5}$.

[...] la somma, che manda il vescovo di Coimbra, acciò come è il più ricco Prelato di questo Regno, cosi non si lasci vincer' di liberalità, et io opera tanto pia et christiana ${ }^{6}$.

Este era, pelo menos, o parecer do colector apostólico em Portugal, Fabio Biondi, transmitido ao cardeal Aldobrandini, em Roma, no ano de 1595.

Fabio Biondi da Montalto (1533-1618), a par de Giovanni Battista Confalonieri (1561-1648), foi um dos principais correspondentes italianos de D. Afonso de Castelo Branco. Com ambos trocou missivas regularmente desde a década de 1590 até ao ano do falecimento do bispo-conde em 1615, em que tratava assuntos vários relativos à diocese de Coimbra e a Portugal e procurava inteirar-se do andamento das suas questões junto da cúria papal.

Segundo José Pedro Paiva, conhecem-se mais de duas centenas de cartas de D. Afonso de Castelo Branco, reunidas no Fondo Confalonieri do Archivio Segreto Vaticano. Este conjunto epistolar reúne informação fundamental para o estudo da figura de D. Afonso de Castelo Branco, nas suas diferentes dimensões ${ }^{7}$. Embora a correspondência proveniente de Itália tenha desaparecido ou esteja por localizar, os dados reunidos são suficientes para caracterizar e enquadrar a política do bispo-conde, cuja actuação e relações pessoais se estenderam muito além dos limites geográficos e de superintendência eclesiástica da cidade de Coimbra, alcançando as mais altas esferas políticas da corte régia filipina e da cúria papal.

Interessa esclarecer quem eram os agentes com quem D. Afonso de Castelo Branco se relacionou e se correspondeu, e os destinatários criteriosamente

5 Carta do colector de Portugal, Fábio Biondi patriarca de Jerusalém, ao cardeal Aldobrandini. Lisboa, 22 de Abril de 1595. Archivio Segreto Vaticano (ASV), Fondo Segretaria di Stato, Portogallo 10, fl. 76v.

6 Carta do colector de Portugal, Fabio Biondi patriarca de Jerusalém, ao cardeal Aldobrandini. Lisboa, 7/10/1595. ASV, Fondo Segretaria di Stato, Portogallo 10, fl. 223.

7 Este artigo foi possível em virtude do generoso contributo do Prof. Doutor José Pedro Paiva, que amavelmente me cedeu as suas transcrições e notas da correspondência de D. Afonso de Castelo Branco conservada no Archivio Segreto. Toda a documentação do ASV - Fondo Confalonieri adiante citada refere-se ao seu levantamento documental. A restante correspondência mencionada, referente ao Fondo Segretaria di Stato, Portogallo, é resultado do meu trabalho de investigação no ASV. 
seleccionados das ofertas, começando pelos seus interlocutores mais directos na cidade do Tibre ${ }^{8}$.

Fabio Biondi foi nomeado patriarca de Jerusalém em 1588 e, por incumbência de Clemente VIII, exerceu o cargo de colector e vice-legado apostólico em Portugal entre 1593 e 1596, acompanhado pelo seu secretário Gianbattista Confalonieri. Foi certamente nestas circunstâncias que o bispo-conde os conheceu e com eles manteve contacto assíduo, antes e após o regresso de ambos a Roma em 1597. O bispo-conde chegou, inclusivamente, a recebê-los em Coimbra, aquando da viagem de peregrinação que o patriarca realizou a Santiago de Compostela em 1594. Seria a Biondi que D. Afonso de Castelo Branco dirigiria, mais tarde, os pedidos de distribuição das ofertas na corte papal, destinadas aos cardeais e aos papas Clemente VIII e Paulo V.

Com Gianbattista Confalonieri, D. Afonso estabeleceu uma relação próxima e de confiança, tendo-o escolhido para seu agente e encarregado de negócios em Roma ${ }^{9}$. Além de interlocutor privilegiado junto dos cardeais, Confalonieri adquiriu livros para enriquecer a biblioteca do antístite português e outros bens, como um retábulo que enviou para Coimbra através do mestre-escola da Sé que regressava nessa ocasião de Roma ${ }^{10}$. D. Afonso de Castelo Branco retribuiu os seus serviços com um ordenado de cem cruzados e soube recompensar a fidelidade do seu agente italiano com outras graças materiais, fazendo remeter ao secretário do patriarca de Jerusalém alguns pares de luvas de âmbar e «um penteador da Índia para se VM lembrar quando se barbear de quão seu servidor sou» ${ }^{11}$.

8 As informações relativas aos cardeais italianos que se seguem foram, em parte, coligidas em MIRANDA, Salvador - The Cardinals of the Holy Roman Church. Última actualização em 22 de Junho de 2014 (http://www2.fiu.edu/ mirandas/cardinals.htm, consultado em 2014.06.23) e nas respectivas entradas de Treccani L'enciclopedia italiana (http://www. treccani.it/, consultado em 2014.06.23).

9 PAIVA, José Pedro-A diocese de Coimbra..., cit., p. 235 n. 30. Além de Confalonieri, D. Afonso mantinha outro agente, Duarte Paulo, a quem pagava trinta mil réis (ou seja, 75 cruzados). Carta de D. Afonso de Castelo Branco a Gianbattista Confalonieri, secretário do patriarca de Jerusalém. Coimbra, 6 de Janeiro de 1597. ASV, Fondo Confalonieri, Vol. 39, fl. 46.

${ }^{10}$ Carta de D. Afonso de Castelo Branco a Gianbattista Confalonieri, secretário do patriarca de Jerusalém. Coimbra, 15 de Janeiro de 1601. ASV, Fondo Confalonieri, Vol. 39, fl. 85.

${ }^{11}$ Carta de D. Afonso de Castelo Branco a Gianbattista Confalonieri, secretário do patriarca de Jerusalém. Coimbra, 6 de Janeiro de 1597. ASV, Fondo Confalonieri, Vol. 39, fl. 46 . 
É possível que também tenha conhecido pessoalmente, em Lisboa, Michele Bonelli (1541-1598), por ocasião da legacia papal que este presidiu, em 1571, a Espanha e Portugal, acompanhado de uma comitiva em que participou Ippolito Aldobrandini, futuro papa Clemente VIII. Professo dominicano e mais conhecido por cardeal Alessandrino, Michele Bonelli foi cardeal nipote de Pio V (1566), ocupando-se de múltiplas questões na cúria romana (construtivas, jurídicas e teológicas), além das missões diplomáticas enquanto legado pontifício nos reinos de França e da Península Ibérica. O cardeal Alessandrino e D. Afonso de Castelo Branco mantiveram, posteriormente, contacto cordial através de correspondência e troca mútua de presentes $^{12}$.

Os representantes apostólicos que sucederam a Fabio Biondi foram também considerados na correspondência e ofertas de D. Afonso. Ferdinando Taverna (1558-1619), descendente de uma família patrícia milanesa, foi apontado para colector de Portugal em 1596. A partir de 1599 ocupou o lugar de Governador de Roma e, em 1604, recebeu a mitra cardinalícia de Sant'Eusebio, por influência do cardeal Pietro Aldobrandini. É já na qualidade de cardeal que o bispo-conde o presenteará, tal como a Domenico Ginnasio (1551-1639), elevado ao cardinalato no mesmo consistório que Taverna, e indigitado para o cargo de núncio papal em Espanha de 1600 a 1605.

Por sua vez, Pietro Aldobrandini (1571-1621), cardeal nipote de Clemente VIII (1593), assumiu uma posição de grande relevo na gestão dos assuntos da corte papal. Na qualidade de secretário de Estado manteve-se informado dos assuntos de Portugal, através das cartas enviadas pelo colector Fabio Biondi, que lhe fez as citadas referências elogiosas sobre D. Afonso de Castelo Branco. O próprio bispo-conde dirigiu-lhe algumas missivas sobre assuntos da gestão da diocese ${ }^{13}$.

O cardeal Montelparo, Gregorio Petrocchini de nome (1535-1612), foi prior geral dos Eremitas de Santo Agostinho entre 1587 e 1591, tendo

O salário era pago através de um veneziano, que tinha por nome Jeronimo Estella. Carta de D. Afonso de Castelo Branco a Gianbattista Confalonieri, secretário do patriarca de Jerusalém. Coimbra, 16 de Março de 1598. ASV, Fondo Confalonieri, Vol. 39, fl. 66.

${ }_{12}$ ASV, Fondo Confalonieri, v. 31, fl. 77 e 132; v. 39, fl. 44.

${ }^{13}$ ASV, Segretaria di Stato, Portogallo 6, fls. 146, 161, 256. 
procedido à visitação dos conventos da ordem em Espanha enquanto comissário apostólico designado por Sisto V. Após o regresso a Roma, em 1589, o mesmo pontífice elevou-o ao cardinalato. Talvez o bispo-conde tivesse tido contacto com Montelparo por ocasião da sua viagem à Península Ibérica.

Alfonso Gesualdo (1540-1603), nobre napolitano e cardeal desde 1561, foi nomeado Protector de Portugal em 1585 e, em 1594, foi transferido da diocese de Ostia e Velletri para a arquidiocese de Nápoles ${ }^{14}$. Há indícios de Afonso Gesualdo se ter correspondido com D. Afonso de Castelo Branco em algumas ocasiões, ao contrário do que sucede com os cardeais Ottaviano Paravicini, Girolamo Mattei, Girolamo Pamphilj e Pompeio Arigoni, cuja relação directa com o bispo-conde ou com os assuntos portugueses carece de outros dados ${ }^{15}$.

Quanto ao cardeal de Cosenza, que o bispo-conde menciona na correspondência, deveria referir-se a Giovanni Evangelista Pallotta (1548-1620), apontado para arcebispo de Cosenza e para o cardinalato em 1587, tendo ocupado, entre outros, os lugares de arcipreste da Basílica de São Pedro e de secretário e sub-deão do Colégio dos Cardeais. Interessaria esclarecer, de facto, de quem se trata, para melhor situar as relações transalpinas de

${ }^{14} \mathrm{O}$ correspondente de D. Afonso de Castelo Branco, Gianbattista Confalonieri, foi secretário de Afonso Gesualdo até ao momento da transferência deste para a arquidiocese de Nápoles (salvo os períodos em que esteve em Espanha e Portugal, ao serviço dos legados papais). Nesta altura, Confalonieri volta a ser secretário de Fábio Biondi. Eventualmente, o contacto do bispo-conde com o cardeal Gesualdo poderá ter sido favorecido por intermédio de Confalonieri.

${ }^{15}$ Ottaviano Paravicini (1552-1611), oratoriano apadrinhado por Cesare Baronio, foi elevado a cardeal em 1591 por Gregório XIV. Por seu turno, Girolamo Mattei (1547-1603), nomeado cardeal em 1586, assumiu em 1591 o cargo de prefeito da importante Sacra Congregatio Cardinalium pro executione et interpretatione concilii Tridentini interpretum, cargo que desempenhou até ao seu falecimento em 1603.

Girolamo Pamphilj (1544-1610) integrou, inicialmente, a casa e corte do cardeal Pietro Aldobrandini. cardeal desde 1604, ocupava o cargo de vigário geral de Roma (1605-10) quando D. Afonso de Castelo Branco lhe enviou porcelanas.

Pompeio Arigoni (1552-1616) no início de carreira foi sucessivamente defensor das causas de Filipe II de Espanha em Roma, advogado consistorial e auditor do Tribunal Apostolicum Rotae Romanae. Depois de eleito cardeal em 1596, veio a ocupar os cargos de datário da Cúria Apostólica sob Leão XI e Paulo V e de secretário da Suprema Sagrada Congregação da Romana e Universal Inquisição (1605-1616). 
D. Afonso de Castelo Branco, dado que pelas suas próprias palavras era «seu amigo antigo» ${ }^{16}$.

Finalmente, refira-se Cesare Baronio (1538-1607) que recebeu, entre outras importantes dignidades, os títulos de Geral da Congregação dos Oratorianos em 1593 e de cardeal em 1596, tendo sido uma figura próxima de São Filippo Neri e de Clemente VIII, dos quais foi discípulo e confessor, respectivamente. A reputada erudição de que beneficiava determinou a sua nomeação, em 1597, para bibliotecário da Santa Igreja Romana. Baronio representou um papel central nos estudos da História da Igreja, tomando a arquitectura como uma das fontes históricas principais para a sua obra monumental, publicada em doze tomos, Annales ecclesiastici a Christo nato ad annum 1198 (1588-1607). D. Afonso de Castelo Branco não só teve conhecimento como se interessou notoriamente pelo trabalho do cardeal Baronio, manifestando intenção de patrocinar a edição dos Anais eclesiásticos com o envio de dez mil cruzados, que o historiador recusou, agradecendo ${ }^{17}$.

\section{Da troca de presentes entre D. Afonso de Castelo Branco e a corte papal}

As desejadas boas relações com a corte papal em Roma traduziram-se pela troca de presentes entre D. Afonso de Castelo Branco e os cardeais e pontífices. A partir de uma carta de D. Afonso ficamos a saber que Clemente VIII lhe remeteu, cerca de 1595 através do seu agente em Roma, «uma boceta de Agnus Dei e de Veronicas, cujo retrato me trouxe em pintura». Recebeu, na mesma ocasião, do cardeal Alfonso Gesualdo «uma cruz de ouro com o Santíssimo lenho, relíquias dos gloriosos Apóstolos S. Tiago S. André e do mártir S. Sebastião»e, pela parte do antigo legado

\footnotetext{
${ }^{16}$ ASV, Fondo Confalonieri, v. 39, fl. 44.

${ }^{17}$ A história é narrada por D. Jerónimo de Mascarenhas $(1639,62)$, na Oração Exortatória e panegírica que proferiu no terceiro dia do sínodo de Coimbra realizado em 1639. MASCARENHAS, Jerónimo de - Oraçam exhortatoria e panegirica (1639) in ALMEIDA, Fortunato - D. Jorge de Almeida e D. Afonso de Castelo Branco, bispos de Coimbra. O Instituto, N. ${ }^{\circ} 71$ (1924).
} 
papal em Espanha e Portugal, cardeal Alessandrino, um «Agnus Dei do Pontífice Pio V seu tio» ${ }^{18}$.

Os artigos muito apreciados com que D. Afonso de Castelo Branco foi presenteado eram símbolos do catolicismo. Se por um lado, as relíquias constituíam fragmentos materiais da devoção a Cristo e aos santos, cujo culto e faculdades milagrosas haviam sido reforçados no Concílio de Trento, o Agnus Dei era uma peça sacramental à qual também se atribuíam especiais virtudes.

Os Agni Dei aqui referidos eram medalhas ovais e de dimensões variáveis feitas com os restos do círio pascal e do óleo do santo crisma. De um lado, cunhava-se a imagem do cordeiro místico, as armas e o nome do papa reinante e a data da consagração; e, do outro, a imagem votiva de um santo. A partir de 1470, passaram a ser consagradas pelos próprios pontífices no ano da sua eleição e depois em ciclos de sete $\operatorname{anos}^{19}$.

Em retribuição aos objectos votivos oferecidos pelo papa Clemente VIII e pelos cardeais Alfonso Gesualdo e Alessandrino, o bispo-conde D. Afonso de Castelo Branco enviou para Roma contas de calambuco e pedras bezoar procedentes das possessões portuguesas das Índias. As contas eram feitas a partir de uma madeira odorífera asiática ${ }^{20}$, mas as pedras bezoar tinham uma

${ }^{18}$ Carta do bispo conde D. Afonso de Castelo Branco ao legado papal Fabio Biondi, Janeiro de 1596. ASV, Fondo Confalonieri, vol. 33, fl. 132. Publ. PAIVA, José Pedro A diocese de Coimbra..., cit., p. 237-38.

${ }^{19}$ A origem desta tradição é incerta, mas pensa-se poder remontar à Antiguidade Tardia ou à Alta Idade Média. Os Agni Dei seriam, inicialmente, usados para protecção contra tormentas, pendurados ao pescoço ou conservados como objecto de devoção. Um dos exemplares mais antigos conhecidos é um Agnus Dei do papa Gregório XI, datado de 1370. Na Época Moderna, estes medalhões eram remetidos pelos pontífices aos soberanos dos estados católicos e aos principais representantes da Igreja, como signo da sua autoridade, embora ainda revestidos do seu simbolismo original. THURSTON, Herbert - Agnus Dei. The Catholic Encyclopedia. Vol. 1. New York: Robert Appleton Company, 1907 (http://www. newadvent.org/cathen/01220a.htm); CASTELLANI, Giuseppe - Agnus Dei. Enciclopedia italiana de scienze, lettere e arte. Roma: Istituto della Enciclopedia Italiana, 1929-1939, vol. 1, col. 901-902. DANTE, Enrico - Agnus dei. Enciclopedia Cattolica. Città del Vaticano: Ente per l'Enciclopedia Cattolica e per il libro cattolico, 1948-1954, vol. 1 col. 490-491. ALMEIDA, Fortunato - História da Igreja ..., cit., vol. II, p. 323 n. 4.

${ }^{20}$ Segundo o padre Rafael Bluteau, calambuco é uma espécie vegetal oriunda da Ásia, uma madeira «de cheiro muito penetrante; e desta espécie vem muito pouca à Europa, porque tem grande preço em Japão, donde dizem, que vale mais de oitenta mil réis o arrátel. Com este precioso aroma perfumam os Japões as casas, e os vestidos. Usam deles os Chins nos acidentes de Paralisia, e na falta dos espíritos vitais». BLUTEAU, Rafael - Vocabulário 
origem insólita, sendo concreções de origem animal usadas como suposto antídoto contra o veneno e a melancolia.

Muito cobiçadas na Europa dos séculos XVI e XVII, as pedras bezoar encontravam-se entre os produtos de origem animal mais dispendiosos, dada a raridade e procura ${ }^{21}$. Eram adquiridas pelos Portugueses nas regiões de Ormuz, Calecute, Cochim, Goa e Malaca, e constituíam ofertas bastante apreciadas pelas principais casas europeias. Tal foi o caso da pedra engastada em filigrana de ouro com que a rainha D. Catarina presenteou o seu irmão, o Imperador Carlos $\mathrm{V}^{22}$. O afortunado possuidor de uma pedra desta qualidade podia usá-la junto ao corpo (pendurada numa corrente ou pulseira), ingeri-la em infusões ou expô-la, pela sua singularidade e valor, na sua câmara de curiosidades e maravilhas, caso dispusesse de uma.

A 24 de Dezembro de 1596, o bispo-conde assinou uma carta dirigida ao cardeal Pietro Aldobrandini, anunciando que pelo

Patriarca de Jerusalém mando a V. Ill. ${ }^{\text {ma }} \mathrm{S}^{\mathrm{a}}$ uma pedra de bazar das melhores, em bondade e quantidade que vieram este ano da Índia. E assim a pode V. Ill. ${ }^{\mathrm{ma}}$ s. ${ }^{\mathrm{a}}$ dar seguramente a Sua Santidade seguramente [sic]. Nosso Senhor a $\mathrm{IIl}^{\mathrm{ma}}$ e $\mathrm{R}^{\mathrm{ma}}$ Pessoa de V.S. per muitos anos guarde e seu estado prospere ${ }^{23}$.

Portuguez e Latino. Coimbra: No Colégio das Artes da Companhia de Jesus, 1712-1728, vol. II, p. 45-46.

${ }^{21}$ Os bezoares mais valorizados eram os de cabras persas e de porcos-espinho, seguidos das concreções de macacos e porcos do Sudeste insular da Ásia, alcançando o preço de 40 vezes o seu peso em ouro ou 650 vezes em prata. Lisboa era o principal centro de distribuição de pedras bezoar na Europa, custando em média 200 cruzados/bezoar. Sobre as proveniências, usos, mercado e circulação deste material vejam-se os estudos BORSCHBERG, Peter - O comércio, uso e falsificação dos bezoares de porco-espinho na Época Moderna (c. 1500-1750). Oriente 14 (2006) 62-77; BORSCHBERG, Peter The Euro-Asian trade in bezoar stones (approx. 1500-1700) in NORTH, Michael (ed.) Artistic and cultural exchanges between Europe and Asia, 1400-1900: rethinking markets, workshops and collections. Aldershot: Ashgate, 2010, p. 29-43.

${ }^{22}$ Relativamente à oferta de D. Catarina e à montagem de bezoares em filigrana de ouro, veja-se GSCHWEND, Annemarie Jordan - As maravilhas do Oriente: colecções de curiosidades renascentistas em Portugal, in SILVA, Nuno Vassallo e (ed.) - A herança de Rauluchantim. Lisboa: Museu de São Roque, 1996, p. 91-92, 119.

${ }^{23}$ Carta de D. Afonso de Castelo Branco ao cardeal Aldobrandino, Coimbra, 24 de Dezembro de 1596. ASV, Segreteria di Stato, Portogallo 6, fl. 265. 
Esta pedra seria a maior das três que seguiram para Roma dez meses depois. A remessa foi enviada ao cuidado do patriarca de Jerusalém, Fabio Biondi, a quem D. Afonso pediu que as entregasse aos respectivos destinatários:

três pedras de Básar mui boas, que somente achei. A maior me fará VIS mercê de dar de minha parte ao Ill. S. cardeal Aldobrandino, que é muito grande e formosa e se pode dar a Sua Santidade. A outra ao Ill S cardeal Gesualdo. E outra ao Ill. cardeal Peravicino ${ }^{24}$.

D. Afonso de Castelo Branco remeteria, noutras ocasiões, mais de trinta outros bezoares «da Índia», que eram, aliás, considerados os de mais elevada qualidade por Confalonieri, conforme relatou na obra Da grandeza e magnificência da cidade de Lisboa: «o bezaar que vem da Índia é de longe melhor do que aquele que trazem do Perú $\rangle^{25}$.

Em Roma, as pedras bezoar não eram transaccionadas nos habituais mercados de luxo, mas em de circuitos de elite muito estritos ${ }^{26}$, o que nos faz pensar no valor precioso das ofertas feitas pelo bispo de Coimbra. $\mathrm{Na}$ corte papal, o apreço pelos bezoares era generalizado. Nem o próprio cardeal Carlo Borromeo, insuspeito pela austeridade e rigor no governo da vida pessoal, escapava à admiração e respeito pelas ditas faculdades terapêuticas deste material. Há mesmo notícia de, em 28 de Junho de 1572, Borromeo ter enviado à sua tia Margherita Trivulzio, esposa do conde Giulio Cesare Borromeo e mãe de Federico Borromeo, a «miracolosa pietra Beezar» que lhe dera o grão-duque de Florença. Estando a tia gravemente

${ }^{24}$ Carta de D. Afonso de Castelo Branco a Fabio Biondi, Outubro de 1597. ASV, Fondo Confalonieri, v. 39, fl. 44. Publ. PAIVA, José Pedro - A diocese de Coimbra..., cit., p. 236.

${ }^{25}$ Por terras de Portugal no século XVI. Bartolomé de Villalba y Estaña, Gianbattista Confalonieri. Lisboa: Comissão Nacional para as Comemorações dos Descobrimentos Portugueses, 2002, p. 220. Como se sabe, as feitorias portuguesas da Índia eram verdadeiras plataformas de circulação dos mais diversos objectos e materiais provenientes de diferentes regiões da Ásia. Segundo Peter Borschberg, o porto de Ormuz foi, por exemplo, o principal centro de escoamento de pedras bezoar provenientes da Pérsia e de Khorasan (região actual do Irão), entre 1507 e 1622. BORSCHBERG, Peter - The Euro-Asian trade..., cit., p. 33.

${ }^{26}$ Segundo Paola Venturelli, os jesuítas mandavam vir este material da Índia e do Perú, tornando-se fornecedores exclusivos de numerosos cardeais em Roma. VENTURELLI, Paola - Splendore e ornamento. Oggetti e materiali preziosi tra Carlo e Federico Borromeo in BISCOTTINI, Paolo (coord.) - Carlo e Federico: la luce dei Borromeo nella Milano spagnola. Milano: [s.n.], 2005, p. 130. 
doente, Carlo acreditava ser a pedra bezoar «cosa pretiosissima et rimedio eficacíssimo contro diverse sorte di mali, rinchiusa in un bottone d' oro della quale si valerà per servitio del conte, havendo poi cura del rimanente per poter servire a qualche altro bisogno» ${ }^{27}$.

O crédito nas propriedades do bezoar na cúria romana era tal, que, quando o papa Clemente VIII adoeceu em 1605 com diagnóstico de envenenamento, a droga prescrita pelos físicos do pontífice foi a dita pedra, recomendando que fosse um exemplar de autenticidade comprovada e de excelente qualidade. Esta notícia motivou, prontamente, o envio de uma pletora de espécimes por parte de bispos, cardeais, dignitários e príncipes de todo o mundo católico para salvar o papa agonizante ${ }^{28}$.

D. Afonso de Castelo Branco revela, assim, o conhecimento dos artigos mais apreciados e apropriados aos destinatários, sabendo eleger itens exclusivos e distintos para as diferentes personalidades que pretendia agraciar. É o que se infere da escolha de «uma peça de calambuco» para presentear o papa Paulo V em 1608, adquirida por 200 cruzados (80 mil réis) e considerada digna do pontífice ${ }^{29}$, bem como de pequenas contas de calambuco para outros destinatários ${ }^{30}$.

As contas de calambuco foram enviadas ao cardeal Mattei, que não quereria bens de maior riqueza segundo as palavras de D. Afonso, e ao cardeal Cesare Baronio, que se recusara a aceitar os dez mil cruzados do bispo de Coimbra para a edição dos Anais Eclesiásticos ${ }^{31}$. Episódio a que D. Afonso faz referência com um jogo de palavras, não sem alguma ironia: «que já noutro tempo não quis contar dinheiro pode contar nas contas os pater nostres que rezar» ${ }^{32}$. Ou seja, uma vez que Baronio declinara a prévia oferta pecuniária, que aceitasse agora as contas de calambuco para fazer um terço.

${ }^{27}$ VENTURELLI, Paola - Splendore e ornamento..., cit., p. 130.

${ }^{28}$ BORSCHBERG, Peter - The Euro-Asian trade..., cit., p. 40.

${ }^{29}$ Carta de D. Afonso de Castelo Branco ao patriarca de Jerusalém, vice-legado no reino de Portugal. Coimbra, 30 de Março de 1608. ASV, Fondo Confalonieri, Vol. 39, fl. 358.

${ }^{30}$ Carta de D. Afonso de Castelo Branco ao patriarca de Jerusalém, vice-legado no reino de Portugal. Coimbra, 6 de Janeiro de 1597. ASV, Fondo Confalonieri, Vol. 39, fl. 44.

${ }^{31}$ MASCARENHAS, Jerónimo de - Oraçam exhortatoria..., cit., p. 62.

${ }^{32}$ Carta de D. Afonso de Castelo Branco a Fabio Biondi, Outubro de 1597. ASV, Fondo Confalonieri, vol. 39, fl. 44. Publ. PAIVA, José Pedro - A diocese de Coimbra..., cit., p. 236. 
Além destas matérias-primas, D. Afonso de Castelo Branco remeteu para Roma ainda outras mercadorias, em particular porcelana importada pelas naus da Índia e luvas de âmbar manufacturadas em Lisboa.

A utilização de baixelas de porcelana da China terá sido um costume introduzido em Roma sensivelmente após o Concílio de Trento, e rapidamente difundido nas décadas seguintes. Sobre esta matéria importa citar um episódio que teve lugar em 1563. Num banquete da corte papal em que participou, D. frei Bartolomeu dos Mártires terá sugerido ao papa Pio IV o uso de baixelas de porcelana em lugar das de prata utilizadas na ocasião. Segundo o arcebispo de Braga, a porcelana adequava-se melhor ao espírito reformador vivido pela Igreja naqueles tempos.

Temos, disse, em Portugal um género de baixela, que com ser barro se avantaja tanto à prata em graça e limpeza, que aconselhara eu a todos os Príncipes que não usarão outro serviço, e desterrarão de suas mesas a prata. Chamamos-lhe em Portugal Porcelanas, vêm da Índia, fazem-se na China. É o barro tão fino e transparente, que as brancas deixam atrás os cristais e alabastros: e as que são variadas de azul enleiam os olhos representando uma composição de alabastro e safiras. O que têm de quebradiço, recompensam com a barateza ${ }^{33}$.

O episódio é narrado por frei Luís de Cacegas e frei Luís de Sousa, autores da biografia do arcebispo de Braga. É interessante e revelador atentar nos termos em que a porcelana chinesa é descrita e valorizada. Por comparação com os metais nobres, o frágil material cerâmico é promovido à categoria de bens magnificentes pelos seus atributos estéticos, equiparados aos dos alabastros, cristais e safiras. Se, por um lado, as baixelas de porcelana eram mais acessíveis - dado o custo de fabrico e a entrada no mercado português de copiosas quantidades destas peças -, por outro, não deixavam de constituir artigos de qualidade e requinte que permitiam manter o nível de sofisticação da mesa na cúria romana, sem investir somas consideradas reprováveis em pleno ano de encerramento do Concílio de Trento. Em suma, e fazendo uso das palavras atribuídas a frei Bartolomeu dos Mártires, as porcelanas enleavam os olhos e recompensavam com a barateza.

${ }^{33}$ SOUSA, Frei Luís de - A vida de Dom frei Bertolameu dos Martyres da Ordem dos Pregadores. Cit. SILVA, Nuno Vassallo e - O culto da porcelana chinesa em Portugal. Artes \& Leilões N. ${ }^{\circ} 6$ (1990) 26. 
A difusão do gosto pela porcelana da China na corte papal é ilustrada pelas mais de três centenas de «porcelanas muito finas» que D. Afonso de Castelo Branco adquiriu em Lisboa, através do seu vedor Luís de Lemos, e enviou para Roma, entre 1606 e 1610, com destino aos cardeais Ginnasio, Arigoni, S. Eusebio, Paravicini, Pamphilj e ao patriarca de Jerusalém. Todavia, a partir do início de Seiscentos, o comércio português da cerâmica chinesa terá sido abalado pela instituição da concorrente Companhia Holandesa das Índias Orientais (VOC), em 1602. Alguns anos depois, o bispo-conde de Coimbra mostraria apreensão a este respeito, pedindo informações a Confalonieri: «dizem-me que hoje se acham em Roma porcelanas mais finas e baratas que em Lisboa que lhe vão por via da Holanda, informe-me VM se é assim» ${ }^{34}$. E, de facto, a partir de 1610 não se registam, na correspondência conhecida, outros envios de porcelana pelo bispo-conde para Roma.

As luvas de âmbar terão sido, igualmente, um artigo com larga aceitação, uma vez que D. Afonso de Castelo Branco depois de uma primeira remessa em 1597 de 24 pares destinados aos cardeais Alessandrino, d'Essa (?), a Gregorio Petrocchini da Montelparo e ao cardeal de Cosenza, enviaria noutras ocasiões mais de 180 pares de luvas, que lhe custaram 300 cruzados e que havia «mandado fazer em Lisboa [...] para mandar aos senhores cardeais meus amigos $»^{35}$.

À partida, poder-se-ia pensar que «âmbar» se referisse à resina fóssil da região do Báltico e, nesse sentido, as ditas luvas seriam, possivelmente, tingidas dessa cor ou decoradas com cabochões. Mas, na verdade, trata-se de luvas de couro perfumado, um acessório muito em voga nas cortes europeias a partir de meados do século XVI, cuja divulgação anda tradicionalmente associada a Catarina de Medici, rainha consorte de França, e a Isabel I, rainha de Inglaterra.

Usadas por homens e mulheres de elevado estatuto social, as luvas finamente executadas em pele eram símbolo de poder político e económico. A partir de meados de Quinhentos, surgem frequentemente representadas na arte do retrato, calçadas ou agarradas numa mão pelas personagens. Basta

\footnotetext{
${ }^{34}$ Carta de D. Afonso de Castelo Branco a Gianbattista Confalonieri. Coimbra, 6 de Dezembro de 1610. ASV, Fondo Confalonieri, Vol. 39, fl. 427.

${ }^{35}$ Carta de D. Afonso de Castelo Branco a Gianbattista Confalonieri. Coimbra, 10 de Fevereiro de 1600. ASV, Fondo Confalonieri, Vol. 39, fl. 77.
} 
recordarmo-nos dos retratos dos monarcas e príncipes das cortes ibéricas pintados por Cristóvão de Morais, António Moro e Alonso Sanchez Coello. Nos dias de hoje, nem a pintura nem os exemplares conservados de luvas da época permitem conhecer a dimensão de requinte acrescentada pelo âmbar - o perfume -, aprimorando-as e redobrando o seu carácter luxuoso.

Esta substância rara, denominada por âmbar cinzento ou âmbar gris, constitui um betume brando e pardo, de origem animal, que adquire uma fragância intensa e muito aromática após ser expelido pelos cachalotes e ficar à deriva no mar exposto ao sol. Conhecida desde a Antiguidade, foi extraordinariamente valorizada no período moderno, quer na Europa quer na Ásia, e mereceu a atenção da literatura científica, embora a sua verdadeira origem se revestisse de algum mistério à época ${ }^{36}$.

O âmbar cinzento era recolhido na costa ocidental africana e nas ilhas do Índico e comercializado em Ormuz, Goa ${ }^{37}$, Malaca, Macau e em Lisboa. As suas aplicações eram diversas, sendo utilizado na farmácia, na confecção de alimentos e bebidas, na indústria dos perfumes e dos couros e, quando convertido em contas e em pedaços, na joalharia perfumada ou na aromatização do interior dos móveis de conter ${ }^{38}$.

${ }^{36}$ Sobre o âmbar cinzento veja-se o estudo de BORSCHBERG, Peter - O comércio de âmbar cinzento asiático na época moderna (séculos XV a XVIII). Oriente 8 (2004) 3-25.

${ }^{37}$ Nos guias práticos redigidos no século XVI para orientar a aquisição de pedrarias em Goa, o âmbar surge a par dos diamantes e rubis, das safiras e espinelas. O exemplar manuscrito mais completo destes manuais data de cerca de 1560-1580. Nele se explica quais eram as características a procurar no âmbar para se fazer uma compra avalizada e quais os preços praticados: «o estimam muito por cá neste reino (...) sendo bom o tem por melhor quem em este reino vale cada onça a cinco cruzados e a cinco e meio e dali para baixo segundo a bondade dele». Transc. e publ. SILVA, Nuno Vassallo e - Subsídios para o estudo do comércio das pedras preciosas em Lisboa, no século XVI, Separata do Boletim Cultural da Assembleia Distrital de Lisboa, III Série N. 91 (1989), 2..$^{\circ}$ tomo, p. 22.

${ }^{38}$ Segundo Peter Borschberg, em 1558, «Amado Lusitano refere que as mulheres da Península Ibérica usavam pendentes de âmbar ao pescoço, para disfarçar odores corporais desagradáveis (próprios e dos outros) bem como para defender os pulmões do ar pestilento». BORSCHBERG, Peter - O comércio de âmbar..., cit., p. 19.

No caso do mobiliário, o Ceremonial Ecclesiastico, segundo o rito romano (1743) de frei Matias de Santa Ana dá preferência ao âmbar para aromatizar os paramentos no interior dos móveis de sacristia, em detrimento de plantas aromáticas: «Dentro das gavetas não se lançarão ervas cheirosas, nem folhas de rosas, ainda que estejam secas, porque geram bichos; mas sim somente alguns bocados de âmbar, ou cousa semelhante». Cit. MARQUES, Cátia Teles e - Nos bastidores da liturgia tridentina. O Mobiliário Monumental e as Sacristias em Portugal do século XVI ao XVIII. Lisboa: [s.n.], 2007. Dissertação de Mestrado em História 
No que se refere às luvas de âmbar, elas eram produzidas em Lisboa nos séculos XVI e XVII. Esta informação é-nos facultada pelo agente de D. Afonso de Castelo Branco, Gianbattista Confalonieri. Na obra que redigiu sobre a capital portuguesa, Confalonieri menciona os perfumistas ali residentes, observando que era em Lisboa que «nasciam as luvas finas de âmbar branca e negra de cinco, 10 e 15 e mais escudos o par. Por tudo isto é esta cidade cheia de algas, almíscar, e outras coisas tais» ${ }^{39}$.

A indústria das luvas de âmbar cinzento foi evidentemente favorecida pelas rotas comerciais marítimas portuguesas, testemunhando a apropriação de novas matérias-primas para acrescentar aos tradicionais acessórios de vestuário um valor de exclusividade que lhes garantiu enorme fama e difusão ${ }^{40}$. D. Afonso de Castelo Branco teve certamente conhecimento da sua aceitação, escolhendo-as por esse motivo para presentear os cardeais em Roma e procedendo a uma encomenda específica para o efeito.

da Arte Moderna apresentada à Faculdade de Ciências Sociais e Humanas da Universidade Nova de Lisboa, vol. I, p. 39.

${ }^{39}$ Por terras de Portugal..., cit.,p. 220.

${ }^{40}$ Além das remessas de luvas de âmbar produzidas em Lisboa enviadas por D. Afonso de Castelo Branco para Roma, a enorme fama e difusão deste artigo é testemunhada pelas centenas de pares que se registam nas licenças de passo emitidas para autorização da entrada de indivíduos (ou comitivas) e respectivos bens em Espanha na primeira metade do século XVII. A título de exemplo, em 1630, no rol de objectos levados de Madrid para Roma pelo cardeal Panfilio contam-se 150 pares de luvas de âmbar, couros de âmbar, onças de âmbar, 6 rosários de calambuco e pasta de âmbar. Esta documentação, estudada por Bernardo García García, mostra que as luvas de âmbar conformavam, na primeira metade do século XVII, uma das tipologias preferenciais de presentes entre as mulheres principais da corte real, como de dignitários e embaixadores estrangeiros e representantes diplomáticos da Santa Sé. GARCÍA GARCÍA, Bernardo - Regalos diplomáticos y bienes suntuarios en la corte española (1580-1665), in GARCÍA SANTO-TOMÁS, Enrique (ed.) - Materia crítica: formas de ócio y de consumo en la cultura áurea. Madrid: Universidad de Navarra, Iberoamericana, Vervuet, 2009, p. 242-243.

Além disso, sabe-se que estas luvas foram, igualmente, exportadas para Inglaterra, sendo as mais caras do mercado. Conhecidas por luvas «ao estilo espanhol», eram de tal forma apreciadas que o seu consumo justificou a sua produção pelos luveiros locais no século XVII. DUGAN, Holly - The ephemeral history of perfume. Scent and sense in Early Modern England. Baltimore: The Johns Hopkins University Press, 2011, p. 126-153. 


\section{O consumo e as estratégias diplomáticas de D. Afonso Castelo Branco}

D. Afonso de Castelo Branco era um consumidor e encomendante esclarecido. Através dos seus agentes, mantinha-se a par do que de melhor havia no mercado, desde a produção lisboeta de objectos artísticos e bens de luxo, às mercadorias da carreira da Índia que aportavam a Lisboa, aproveitando estas ocasiões para mandar adquirir os artigos com que presenteou as dignidades eclesiásticas da corte papal. As compras e comissões que realizou visaram, além das ofertas diplomáticas, o provimento da Sé de Coimbra e o consumo particular do bispo-conde, como foi o caso das «charamelas e alcatifas» pedidas em 1597 a Matias de Albuquerque, vice-rei da Índia (1591-1597), aquando do seu regresso à metrópole ${ }^{41}$.

Como membro da elite senhorial, por via da ascendência familiar e dos altos cargos eclesiásticos desempenhados, D. Afonso não se envolvia directamente na procura e selecção dos artigos ou nas transacções comerciais, delegando essa responsabilidade em mediadores. Como procuradores privilegiados, eram os seus legados que procediam às aquisições, encomendas e contratos que tinha planeado.

De igual forma, a logística do transporte era organizada por gente da sua confiança, já que suspeitava da eficácia das vias de correspondência normais, procurando evitar os oficiais aduaneiros e os guardas dos portos secos. A este propósito, em carta a Gianbattista Confalonieri, D. Afonso de Castelo Branco informa que comprara

treze pedras de bezoar mui formosos nas naus da Índia e oitenta pares de luvas de âmbar e não as mandava porque lhe disse o jesuíta Francisco Pereira que não se pode mandar nada por terra com as ladroíces dos aduaneiros e guardas dos portos secos que até as contas por onde rezava lhe tirarão ${ }^{42}$.

${ }^{41}$ Carta de D. Afonso de Castelo Branco. Coimbra, 20 de Outubro de 1597. ASV, Fondo Confalonieri, Vol. 31, Tomo 5, fl. 173. Sobre as peças encomendadas em Lisboa para a Sé e conventos de Coimbra - sedas, a pintura, o lavabo e os azulejos da sacristia, retábulo da igreja do convento de Santa Ana e sepulcro de prata da rainha santa D. Isabel -, veja-se MARQUES, Cátia Teles e - A sacristia e a encomenda ..., cit..

${ }^{42}$ Carta de D. Afonso de Castelo Branco a Gianbattista Confalonieri. 10 de Outubro de 1604. ASV, Fondo Confalonieri, Vol. 39, fl. 198. 
Por essa razão e quando possível remetia as ofertas para Roma através de intermediários seus. Foi o que sucedeu, como se viu atrás, com as pedras de bezoar, contas de calambuco e luvas de âmbar entregues ao legado papal que se encontrava em Lisboa em 1597, Fabio Biondi, para serem distribuídas pelos cardeais. Quem procedeu à remessa foi Jorge Fernandes, criado do bispo-conde, que acompanhou a legacia até Itália, levando também consigo um escritório da China e um penteador da Índia, além de iguarias para a viagem ${ }^{43}$.

No que se refere à selecção dos artigos, a correspondência do bispo de Coimbra mostra uma clara preferência pelo universo material dos territórios de Além-Mar, abarcando matérias-primas com supostas propriedades terapêuticas - contas de calambuco e pedras bezoar - e mercadorias sofisticadas - porcelana e mobiliário, têxteis (exemplificado pelo penteador), e luvas feitas em Lisboa, mas perfumadas com o âmbar cinzento trazido pelas naus das Índias. D. Afonso de Castelo Branco remeteu para Roma, ainda, especialidades culinárias portuguesas - barris de lampreias em conserva, empadas de lampreia, presuntos de Lamego e caixas de marmelada e canários, que, como se sabe, são originários dos arquipélagos das Canárias, dos Açores e da Madeira, admirados pelo seu canto harmonioso ${ }^{44}$.

A este propósito, é interessante destacar o contraste entre os objectos de culto religioso remetidos pelos cardeais Alfonso Gesualdo e Alessandrino e pelo papa Clemente VIII para Coimbra e os presentes "mundanos" e de uso pessoal enviados por D. Afonso de Castelo Branco para Roma. Beneficiando do acesso privilegiado aos artigos provenientes das possessões ultramarinas, o bispo-conde de Coimbra revela participar de uma cultura material que se terá consolidado na corte portuguesa sobretudo ao longo do século $\mathrm{XVI}^{45}$.

${ }^{43}$ Carta de D. Afonso de Castelo Branco ao patriarca de Jerusalém, vice-legado no reino de Portugal. Coimbra, 6 de Janeiro de 1597. ASV, Fondo Confalonieri, Vol. 39, fl. 44. Jorge Fernandes iria servir Fabio Biondi, durante a sua estadia em Roma: «o caminho em que com muito gosto acompanhara VIS para o servir nele e ver Roma que na verdade é a corte dos clérigos».

${ }^{44}$ ASV, Fondo Confalonieri, Vol. 31, Tomo 5, fl. 141; Vol. 39, fl. 44, 394.

${ }^{45}$ Sobre esta mudança, veja-se MOREIRA, Rafael - A importação de obras de arte em Portugal no século XVI, in CURVELO, Alexandra et al (coord.) - Da Flandres e do Oriente. Escultura importada: colecção Miguel Pinto. Lisboa: Instituto Português de Museus; Casa-Museu Dr. Anastácio Gonçalves, 2002, p. 11-21; SÁ, Isabel dos Guimarães - The uses of luxury: some exemples from the Portuguese courts from 1480 to 1580 . Análise Social, Vol. XLIV N. ${ }^{\circ} 192$ (2009) 589-604. 
Com o estabelecimento das rotas marítimas e das feitorias nas possessões de Além-Mar foram chegando mercadorias em quantidade suficiente para gerar novos hábitos de consumo e de etiqueta na esfera das elites. De modo que os objectos escolhidos por D. Afonso se tratavam de artigos exclusivos, mas consensualmente aceites à época. Constituíam, por isso, presentes seguros para agradar aos destinatários da cúria romana e os recordar do apoio às causas do bispo-conde.

Em última análise, a divulgação das mercadorias provenientes das Índias Orientais junto da cúria romana, no exercício da diplomacia, poderá ter favorecido a disseminação e consolidação do gosto por alguns artigos em particular e estimulado a sua procura. Sabe-se que, na primeira metade de Seiscentos, os núncios e colectores apostólicos em Portugal e Espanha levavam consigo quantidades apreciáveis de toda a sorte de bens sumptuários aí adquiridos no regresso à península itálica. Segundo Bernardo García,

los embajadores italianos y los nuncios siguieron desempeñando un papel primordial en la exportación e importación de bienes de lujo y obras de arte como puede apreciarse claramente en el estudio de las licencias de paso relacionadas con su entrada y salida de la península ${ }^{46}$.

Desconheço, porém, se estas escolhas se tratavam de uma prática comum no foro da diplomacia praticada pelo clero português, em virtude da escassez de estudos de caso. Só à luz de outros dados será possível avaliar com rigor a singularidade da actuação de D. Afonso de Castelo Branco e identificar e caracterizar padrões de consumo associados à diplomacia eclesiástica, de resto pouco estudada para o período em análise $\mathrm{e}^{47}$.

$\mathrm{Na}$ verdade, a escolha destas mercadorias para oferta encontra-se tradicionalmente associada ao poder régio. Inicialmente extraordinárias pela sua exclusividade, elas passaram a servir propósitos de propaganda política ao serem incluídas no conjunto dos presentes diplomáticos dos reis

${ }^{46}$ GARCÍA GARCÍA, Bernardo - Regalos diplomáticos..., cit., p. 242.

${ }^{47}$ A título de exemplo, veja-se o capítulo da História da Igreja em Portugal de Fortunato de Almeida sobre a troca de presentes entre Portugal e a Santa Sé na Época Moderna, no qual não se sai da esfera régia, não se mencionando quaisquer ofertas por parte dos prelados portugueses à cúria romana. ALMEIDA, Fortunato - História da Igreja..., cit., vol. II, p. 322-327. De 1968 a esta parte, pouco se tem avançado neste tema, com algumas excepções, de que se destaca o trabalho PAIVA, José Pedro - A diocese de Coimbra..., cit.. 
portugueses logo a partir de meados do século $\mathrm{XV}^{48}$. Embora recorrendo ao mesmo universo material, a escala de representação e o nível das ofertas do bispo-conde não competiam com a retórica de uma embaixada régia. Nem podiam fazê-lo, fosse por razões económicas e de estatuto, como por questões de decoro, dado o grau mais moderado de representação se adequar melhor a um prelado.

Em pleno período pós-Trento, o modelo ideal de conduta de um bispo ditava um proceder discreto, reservando as encomendas de aparato para o culto divino, nomeadamente o provimento da Sé - que era, aliás, uma obrigação do múnus episcopal-, ou de igrejas e conventos do seu patrocínio particular. D. Afonso de Castelo Branco foi, neste particular, um mecenas notável no contexto eclesiástico português pós-Trento, como procurei demonstrar noutro lugar ${ }^{49}$.

No entanto, os episódios passados com os cardeais Girolamo Mattei e Cesare Baronio, que recusaram os bens de maior riqueza e o patrocínio oferecidos pelo bispo-conde de Coimbra, se, por um lado, são bem representativos desse espírito reformador que apelava a uma maior austeridade, por outro parecem denunciar que a generosidade de D. Afonso estaria acima do ordinário no âmbito da diplomacia eclesiástica.

Os presentes oferecidos por D. Afonso de Castelo Branco aos papas e cardeais, sem serem objectos de pródiga magnificência ao nível de um soberano, não deixavam de ter um valor apreciável. Sobretudo constituíam gentilezas codificadas pela etiqueta de corte e convertidas por D. Afonso em instrumentos da sua diplomacia. Gestos que indo ao encontro do estatuto, gosto e sensibilidade dos destinatários fariam com que estes se lembrassem e estimassem aquele que os agraciava ${ }^{50}$.

${ }^{48}$ COSTA, João Paulo Oliveira e - O Império Marítimo, in COSTA, João Paulo Oliveira e (coord.), História da Expansão e do Império Português. Lisboa: A Esfera dos Livros, 2014, p. 157.

${ }^{49}$ MARQUES, Cátia Teles e - A sacristia e a encomenda ..., cit..

${ }^{50}$ Carla Alferes Pinto conclui, num estudo sobre a embaixada régia ao Xá da Pérsia de 1622, que dos presentes «dependia muitas vezes o apreço por uma delegação e a atenção que se dava ao assunto da mesma, eles asseguravam a reciprocidade e potenciavam o respeito que se tinha por um ou outro rei, xá, rajá ou czar, além de servirem de admiráveis provas de riqueza, de grandiosidade, da mestria artesanal e plástica de cada corte e do bom gosto dos soberanos». PINTO, Carla Alferes - Presentes ibéricos e «goeses» para 'Abbas I: a produção e consumo de arte e os presentes oferecidos ao Xá da Pérsia por D. García de 
Neste sentido, o envio continuado de presentes fazia parte de uma estratégia de auto-representação de D. Afonso, que passava pela construção calculada de uma imagem diferenciada e favorável a seu respeito em Roma, em detrimento de outros prelados. Esta intenção é mesmo revelada numa das cartas que acompanhava as ofertas:

Ao colector que vem me fará VIS mercê de dizer que aqui tem o bispo de Coimbra tão amigo das causas da Santa Sé Apostólica como ele e que o saberá mui bem servir. E pode VIS com muita razão dizer a Sua Santidade e ao Sagrado Colégio que em bom governo convém fazer diferença dos prelados que bem servem a outros que não fazem o mesmo ${ }^{51}$.

O propósito das doações de D. Afonso de Castelo Branco não pode, por esta razão, ser desligado da aspiração ao favorecimento dos seus interesses e causas pessoais junto da corte papal, da mesma forma que as ofertas dos cardeais e papas ao bispo português tinham o desígnio de o fidelizar à causa romana.

Como salientou José Pedro Paiva, o bispo-conde foi «um sábio utilizador de subtis formas de suborno, com o fito de criar condições favoráveis à aceitação das suas pretensões nos palcos onde decisões importantes eram tomadas $\rangle^{52}$. E os seus intentos passavam, em grande medida, pelas decisões da Santa Sé. De facto, este tipo de actuação foi recorrente e encontra-se bem documentado na correspondência de D. Afonso conservada no Archivio Segreto Vaticano. Apenas para acrescentar outro exemplo, na missiva dirigida ao cardeal Aldobrandini, em que dá conta do donativo de cinco mil cruzados ao papa para financiamento da guerra contra o Turco, D. Afonso não perde a ocasião para solicitar a mercê de duas dispensas

Silva y Figueroa e D. frei Aleixo de Meneses, in LOUREIRO, Rui Manuel e RESENDE, Vasco (coord.) - Estudos sobre Don García de Silva y Figueroa e os «Comentários» da embaixada à Pérsia (1614-1624). Lisboa: Centro de História de Além-Mar, Universidade Nova de Lisboa, Universidade dos Açores, 2011. p. 246.

${ }^{51}$ Carta de D. Afonso de Castelo Branco ao colector de Portugal, Fábio Biondi patriarca de Jerusalém. Outubro de 1597. ASV, Fondo Confalonieri, vol. 39, fl. 44. Publ. PAIVA, José Pedro - A diocese de Coimbra..., cit., p. 236.

${ }^{52}$ PAIVA, José Pedro - A diocese de Coimbra..., cit., p. 235. 
de parentesco para familiares seus ${ }^{53}$. O bispo de Coimbra não deixava, assim, de aproveitar as oportunidades que se lhe ofereciam em proveito das suas causas.

Os códigos políticos e de etiqueta praticados por D. Afonso de Castelo Branco terão procedido da sua convivência na corte régia, antes e após a crise dinástica, onde foi adquirindo experiência na gestão das redes clientelares. De igual modo, nos meios de elite por onde se moveu pôde partilhar de uma cultura material que, ao longo do século XVI, se foi tornando mais cosmopolita com a incorporação nos hábitos de consumo de uma miríade de novos objectos e de matérias-primas provenientes de diversas partes do mundo. Atento às oscilações do gosto e ao mercado, o bispo-conde de Coimbra serviu-se da cultura material como instrumento da diplomacia eclesiástica que praticou de forma inteligente. O investimento em ofertas exclusivas garantia-lhe o reconhecimento do seu prestígio e estatuto, procurando alcançar, deste modo, as desejadas boas relações com a corte papal.

\section{Fontes manuscritas - correspondência de D. Afonso de Castelo Branco}

\section{$\underline{\text { Archivio Segreto Vaticano }}$}

Fondo Segretaria di Stato, Portogallo 10, fl. 76v, 223.

Fondo Segreteria di Stato, Portogallo 6, fl. 146, 161, 256, 265.

Fondo Confalonieri, Vol. 31, Tomo 5, fl. 77, 132, 141, 173.

Fondo Confalonieri, vol. 39, fl. 44, 46, 66, 77, 85, 198, 358, 394, 427.

${ }^{53}$ Carta do bispo conde D. Afonso de Castelo Branco ao cardeal Aldobrandini, 20 de Abril de 1596. ASV, Segreteria di Stato, Portogallo 6, fl. 146. 


\section{Bibliografia}

ALMEIDA, Fortunato - História da Igreja em Portugal. Lisboa: Livraria Civilização Editora, 1968, vol. II.

BLUTEAU, Rafael - Vocabulário Portuguez e Latino. Coimbra: No Colégio das Artes da Companhia de Jesus, 1712-1728, vol. II e V.

BORSCHBERG, Peter - O comércio de âmbar cinzento asiático na época moderna (séculos XV a XVIII). Oriente 8 (2004) 3-25.

BORSCHBERG, Peter - O comércio, uso e falsificação dos bezoares de porco-espinho na Época Moderna (c. 1500-1750). Oriente 14 (2006) 62-77.

BORSCHBERG, Peter - The Euro-Asian trade in bezoar stones (approx. 1500-1700) in NORTH, Michael (ed.) - Artistic and cultural exchanges between Europe and Asia, 1400-1900: rethinking markets, workshops and collections. Aldershot: Ashgate, 2010, p. 29-43.

CASTELLANI, Giuseppe - Agnus Dei. Enciclopedia italiana de scienze, lettere e arte. Roma: Istituto della Enciclopedia Italiana, 1929-1939, vol. 1, col. 901-902.

COSTA, João Paulo Oliveira e (coord.), História da Expansão e do Império Português. Lisboa: A Esfera dos Livros, 2014.

DANTE, Enrico - Agnus dei. Enciclopedia Cattolica. Città del Vaticano: Ente per l'Enciclopedia Cattolica e per il libro cattolico, 1948-1954, vol. 1, col. 490-491.

DUGAN, Holly - The ephemeral history of perfume. Scent and sense in Early Modern England. Baltimore: The Johns Hopkins University Press, 2011, p. 126-153.

GARCÍA GARCÍA, Bernardo - Regalos diplomáticos y bienes suntuarios en la corte española (1580-1665), in GARCÍA SANTO-TOMÁS, Enrique (ed.) - Materia crítica: formas de ócio y de consumo en la cultura áurea. Madrid: Universidad de Navarra, Iberoamericana, Vervuet, 2009, p. 213-251.

GSCHWEND, Annemarie Jordan - As maravilhas do Oriente: colecções de curiosidades renascentistas em Portugal, in SILVA, Nuno Vassallo e (ed.) - A herança de Rauluchantim. Lisboa: Museu de São Roque, 1996, p. 82-127. 
MARQUES, Cátia Teles e - Nos bastidores da liturgia tridentina. O Mobiliário Monumental e as Sacristias em Portugal do século XVI ao XVIII. Lisboa: [s.n.], 2007. Dissertação de Mestrado em História da Arte Moderna apresentada à Faculdade de Ciências Sociais e Humanas da Universidade Nova de Lisboa. 2 vol.

MARQUES, Cátia Teles e - A sacristia e a encomenda episcopal em Portugal no periodo da Reforma Católica. O caso da Sé de Coimbra e o patrocínio do bispo D. Afonso de Castelo Branco. Lisboa: [s.n.], 2013. Tese de Doutoramento em História da Arte Moderna apresentada à Faculdade de Ciências Sociais e Humanas da Universidade Nova de Lisboa.

MASCARENHAS, Jerónimo de - Oraçam exhortatoria e panegirica (1639) in ALMEIDA, Fortunato - D. Jorge de Almeida e D. Afonso de Castelo Branco, bispos de Coimbra. O Instituto, N. ${ }^{\circ} 71$ (1924) 57-64.

MIRANDA, Salvador - The Cardinals of the Holy Roman Church. Última actualização em 22 de Junho de 2014 (http://www2.fiu.edu/ mirandas/ cardinals.htm, consultado em 2014.06.23).

MOREIRA, Rafael - A importação de obras de arte em Portugal no século XVI, in CURVELO, Alexandra et al (coord.) - Da Flandres e do Oriente. Escultura importada: colecção Miguel Pinto. Lisboa: Instituto Português de Museus; Casa -Museu Dr. Anastácio Gonçalves, 2002, p. 11-21.

PAIVA, José Pedro - A diocese de Coimbra antes e depois do Concílio de Trento: D. Jorge de Almeida e D. Afonso Castelo Branco in Sé Velha de Coimbra: culto e cultura. Coimbra: Catedral de Santa Maria de Coimbra, 2005, p. 225-253.

PINTO, Carla Alferes - Presentes ibéricos e «goeses» para 'Abbas I: a produção e consumo de arte e os presentes oferecidos ao Xá da Pérsia por D. García de Silva y Figueroa e D. frei Aleixo de Menses, in LOUREIRO, Rui Manuel e RESENDE, Vasco (coord.) - Estudos sobre Don García de Silva y Figueroa e os «Comentários» da embaixada à Pérsia (1614-1624). Lisboa: Centro de História de Além-Mar, Universidade Nova de Lisboa, Universidade dos Açores, 2011, p. 245-278.

Por terras de Portugal no século XVI. Bartolomé de Villalba y Estaña, Gianbattista Confalonieri. Lisboa: Comissão Nacional para as Comemorações dos Descobrimentos Portugueses, 2002. 
SÁ, Isabel dos Guimarães - The uses of luxury: some exemples from the Portuguese courts from 1480 to 1580 . Análise Social, Vol. XLIV N. ${ }^{o} 192$ (2009) 589-604.

SILVA, Nuno Vassallo e - Subsídios para o estudo do comércio das pedras preciosas em Lisboa, no século XVI, Separata do Boletim Cultural da Assembleia Distrital de Lisboa, III Série N. ${ }^{\circ} 91$ (1989) 2..$^{\circ}$ tomo.

SILVA, Nuno Vassallo e - O culto da porcelana chinesa em Portugal. Artes \& Leilões N. ${ }^{\circ} 6$ (1990) 23-32.

SILVA, Nuno Vassallo e - A recepção de objectos de arte orientais em Portugal (notas para o seu estudo), in SILVA, Nuno Vassallo e (coord). - No caminho do Japão. Arte oriental nas colecções da Santa Casa da Misericórdia de Lisboa. Lisboa: Santa Casa da Misericórdia, 1993, p. $15-22$.

SCALLA, Mirella. 1985. Aspetti teorici della commitenza negli Annales Ecclesiastici di Cesare Baronio in MAIO, Romeo De Maio et al. (coord.) - Baronio e l'arte : atti del Convegno internazionale di studi: Sora, 10-13 ottobre 1984. Sora: Centro di studi sorani Vincenzo Patriarca, 1985, p. 261-287.

THURSTON, Herbert - Agnus Dei. The Catholic Encyclopedia. New York: Robert Appleton Company, 1907, vol. I (http://www.newadvent.org/ cathen/01220a.htm, consultado em 2014.06.22)

Treccani L'enciclopedia italiana. [s.1.]: Istituto Treccani. (http://www. treccani.it/, consultado em 2014.06.23).

VENTURELLI, Paola - Splendore e ornamento. Oggetti e materiali preziosi tra Carlo e Federico Borromeo in BISCOTTINI, Paolo (coord.) - Carlo e Federico: la luce dei Borromeo nella Milano spagnola. Milano: [s.n.], 2005, p. 123-134. 